\title{
Supporting Information for: \\ Water Dissociative Adsorption on NiO(111): \\ Energetics and Structure of the Hydroxylated Surface
}

Wei Zhao $^{\dagger}$, Michal Bajdich ${ }^{\ddagger}$, Spencer Carey ${ }^{\dagger}$ Aleksandra Vojvodic ${ }^{\ddagger}$, Jens K. Nørskov ${ }^{\ddagger}$ and Charles T. Campbell ${ }^{\dagger *}$

* Corresponding author: email= charliec@uw.edu , tel.=206-616-6085

Figure S1. (a) Top and (b) side views of single water molecularly adsorbed on top of Oocto $(4 \times 4) / \mathrm{Ni}(111)(5 \times 5)$ pre-covered with $0.25 \mathrm{ML}$ of dissociated water, giving $-\Delta \mathrm{E}=103.3 \mathrm{~kJ} / \mathrm{mol}$ for the molecular adsorption part.

a)

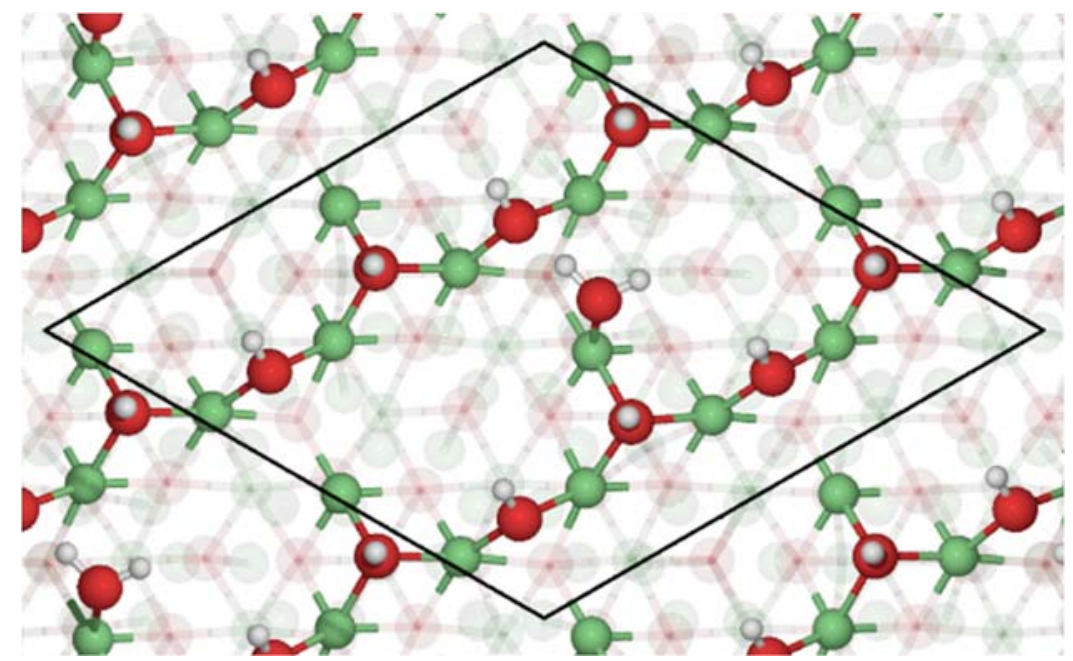

b)

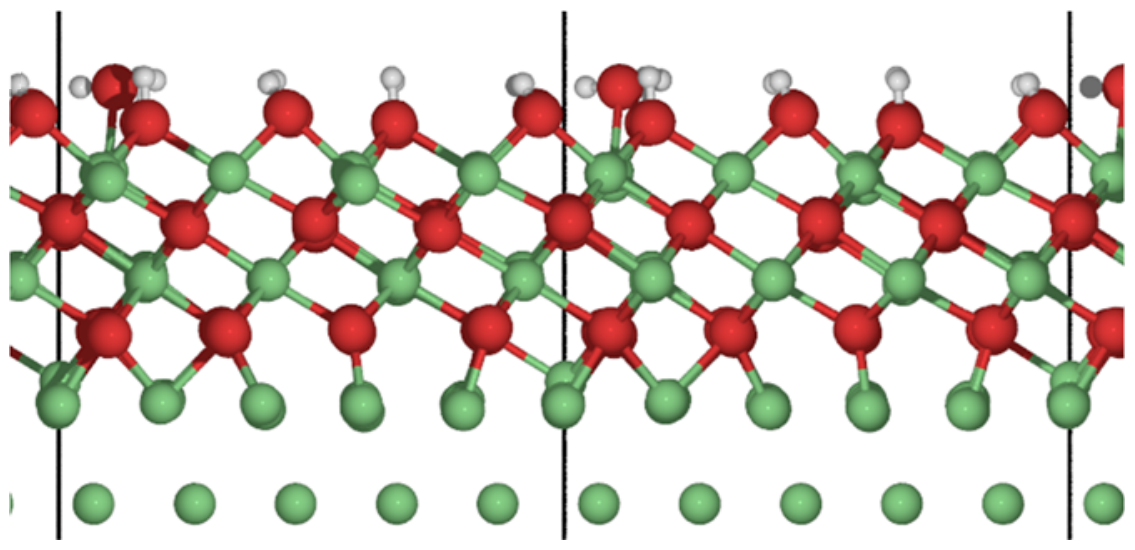


Figure S2: Simulated TP-XPS spectrum with a heating rate of $1.7 \mathrm{~K} / \mathrm{s}$ assuming first-order associative desorption kinetics with a prefactor of $10^{17} \mathrm{~s}^{-1}$, and starting at $200 \mathrm{~K}$ with an initial coverage $(\Theta)$ of $0.25 \mathrm{ML}$ of dissociated water. The desorption activation energy is described as $\mathrm{E}_{\text {des }}=\Delta \mathrm{H}_{\mathrm{ad}}-1 / 2 \mathrm{RT}$, where $\Delta \mathrm{H}_{\mathrm{ad}}$ varies with coverage as $\Delta \mathrm{H}_{\mathrm{ad}}=170-282 \Theta$ while $\Theta<0.18 \mathrm{ML}$ (obtained by linearly fitting the calorimetric dissociative adsorption heats below $0.18 \mathrm{ML}$ ) and $\Delta \mathrm{H}_{\mathrm{ad}}=117 \mathrm{~kJ} / \mathrm{mol}$ while $\Theta \geq 0.18 \mathrm{ML}$ (see Fig. 4).

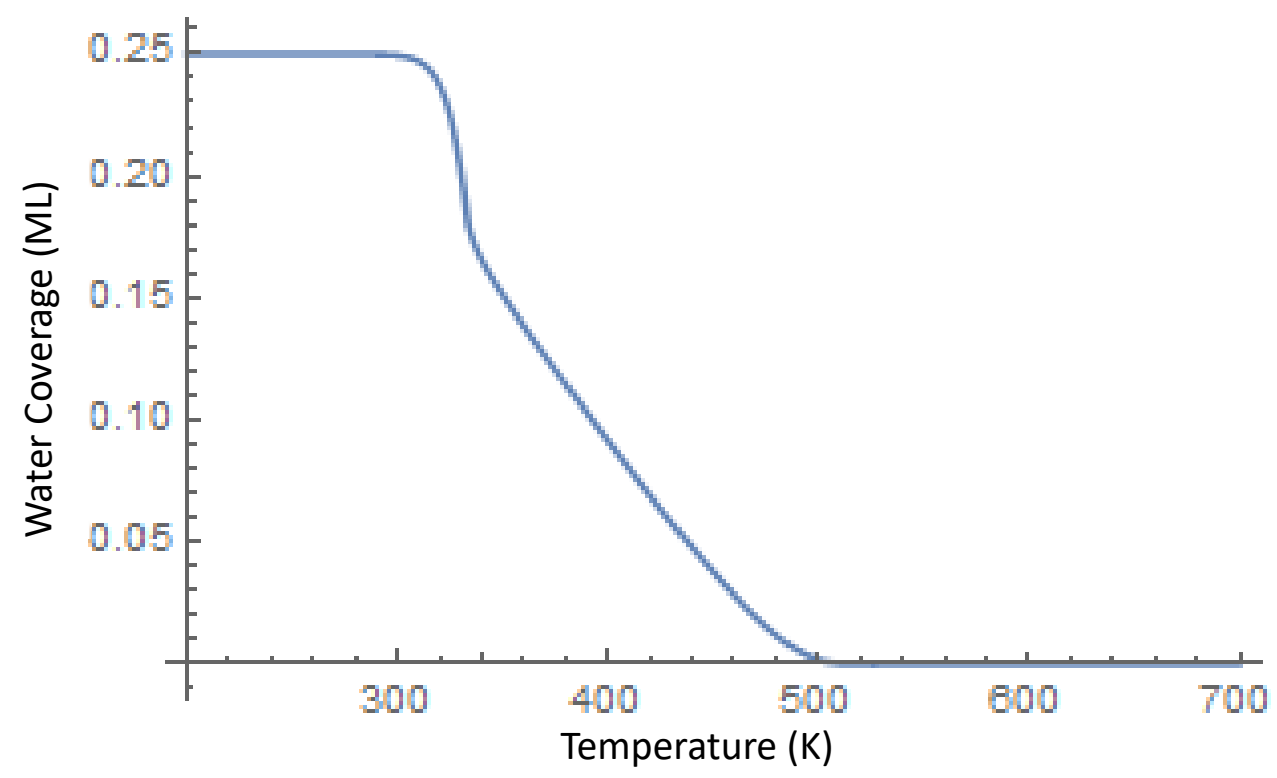


Figure S3: Dependences of the energies of dissociative $\mathrm{H}_{2} \mathrm{O}, \mathrm{H}$ and $\mathrm{OH}$ adsorption on the O-octo surface at 1/16 ML coverage, calculated with the $\mathrm{PBE}+\mathrm{U}$ functional, upon the value of the Hubbard-U parameter.

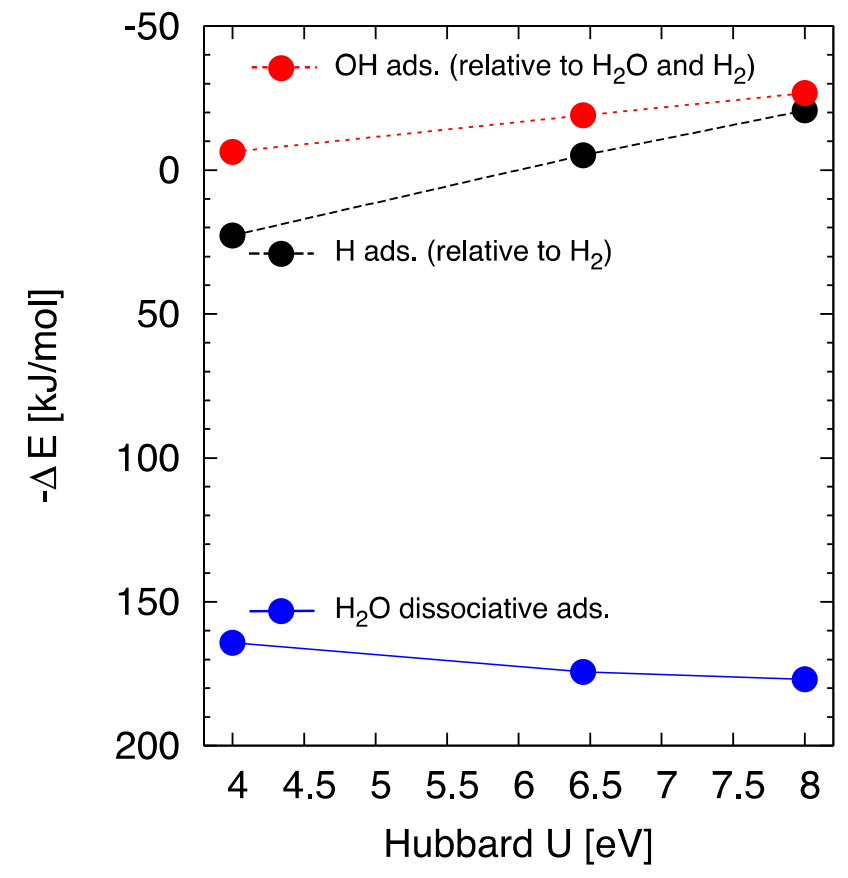

Table S1: Relative surface energies $(\gamma)$ of the lowest water-free and water-adsorbed neutral $\mathrm{NiO}(111)$ surfaces measured against the O-octo surface $\left(E_{\text {surf. }}=0.860 \mathrm{eV}=1.821 \mathrm{~J} / \mathrm{m}^{2}\right)$. The numbers were obtained from 6-layer symmetric slabs within $\mathrm{PBE}+\mathrm{U}(\mathrm{U}=6.45 \mathrm{eV})$ method.

\begin{tabular}{|l|c|c|}
\hline$\Delta \gamma[\mathrm{eV} /(1 \times 1)]$ & no $\mathrm{H}_{2} \mathrm{O}$ & with $\mathrm{H}_{2} \mathrm{O}$ \\
\hline $\begin{array}{l}\mathrm{O} \text {-octo } \\
p(2 \times 2)\end{array}$ & 0.0 & -0.482 \\
\hline $\begin{array}{l}\mathrm{M} \text {-octo } \\
p(2 \times 2)\end{array}$ & 0.029 & -0.323 \\
\hline $\begin{array}{l}\mathrm{O} \text {-miss-row } \\
p(2 \times 1)\end{array}$ & 0.271 & -0.447 \\
\hline $\begin{array}{l}\mathrm{Rt} 3-\mathrm{O}-\mathrm{OH} \\
p(\sqrt{3} \times \sqrt{3})\end{array}$ & - & -0.269 \\
\hline $\begin{array}{l}\mathrm{OH} \\
p(1 \times 1)\end{array}$ & - & -1.009 \\
\hline
\end{tabular}


Table S2: Calculated zero-point energy and heat capacity corrections to the enthalpy of $\mathrm{D}_{2} \mathrm{O}$ adsorption at $300 \mathrm{~K}$ within the harmonic approximation, in units of $\mathrm{kJ} / \mathrm{mol}$.

\begin{tabular}{|l|l|l|l|l|}
\hline & $\mathrm{D}_{2} \mathrm{O}(\mathrm{g})$ & $\mathrm{D}_{\text {ads. }}$ & $\mathrm{DO}_{\text {ads }}$ & $\mathrm{D}_{\text {ads. }}+\mathrm{DO}_{\text {ads.- }} \mathrm{D}_{2} \mathrm{O}(\mathrm{g})$ \\
\hline $\mathrm{ZPE}$ & 39.7 (exp.) & 22.5 & 31.6 & 14.4 \\
\hline $\mathrm{C}_{\mathrm{p}}(0 \mathrm{~K}$ to $300 \mathrm{~K})$ & 9.9 (exp.) & 0.9 & 3.3 & -5.7 \\
\hline $\mathrm{P} \Delta \mathrm{V}(300 \mathrm{~K})$ & 2.5 (RT) & & & -2.5 \\
\hline Totals & & & & 6.2 \\
\hline
\end{tabular}

